ISSN: $1130-3743$

DOI: http://dx.doi.org/10.14201/teoredu201426177101

\title{
EDUCACIÓN TEATRAL: UNA PROPUESTA DE SISTEMATIZACIÓN
}

\section{Theatre Education: a proposal for systematization}

\section{L'éducation théâtrale: une proposition de systématisation}

\author{
Manuel Francisco VIEITES García \\ Universidad de Vigo. Facultad de Ciencias de la Educación. Departamento de \\ Análisis e Intervención Psicosocioeducativa. Avenida Castelao, s/n. Campus \\ Universitario de Orense.32004 Orense (España).Correo-e: mvieites@uvigo.es
}

Fecha de recepción: enero de 2014

Fecha de aceptación: abril de 2014

Biblid [(1130-3743) 26, 1-2014, 77-101]

\section{RESUMEN}

Con el paso de los siglos se desarrolla un conjunto de prácticas formativas que configuran el campo de la educación teatral. En España, salvo excepciones, la idea de una educación teatral que vaya más allá de la formación de creadores escénicos en ningún caso goza, pese a sus potencialidades, de una posición similar a la que presenta en países de nuestro entorno. Sin embargo, la integración de los estudios superiores de arte dramático en el Espacio Europeo de la Educación Superior, junto a la presencia en su currículo de una materia de formación básica denominada "pedagogía", hace necesaria la consideración del campo en el que habrán de desarrollar sus actividades los especialistas en pedagogía teatral. Con este trabajo formulamos una aproximación de carácter teórico al campo de la educación teatral y una propuesta de sistematización, con implicaciones en su estudio desde una perspectiva científica y en la formación de formadores. 
Palabras clave: educación teatral, pedagogía teatral, expresión dramática, expresión teatral, teatro en la educación.

\section{SUMMARY}

Over the centuries, a diverse set of educational practices gave rise to the field of theatre education, which has been enjoying a growing importance in many countries. In Spain the idea of a theatre education that went beyond the training of theatre artists did not come to gain a similar position to that which it occupies in the countries of our cultural area, despite its potential. However, the recent integration of the colleges of dramatic art in the European Higher Education Area, together with the presence in the curriculum of a basic training area called "pedagogy" requires the consideration of the educational field where the specialists in theatre pedagogy are expected to develop their educational practice. With this paper we offer a theoretical overview of the field of theatre education and a systematization of it, with clear implications for a specific research from a scientific perspective but also in the training of trainers.

Key words: theatre education, theatre pedagogy, creative drama, educational theatre, theatre in education.

\section{SOMMAIRE}

Tout au long des siècles un ensemble de pratiques formatives qui configurent le domaine de l'éducation théâtrale se sont développés. En Espagne l'idée d'une éducation théâtrale qui puisse être au-delà de la formation de créateurs théâtraux n'occupe, en aucun cas, malgré ses potentialités, une position semblable à celle qui présente dans des pays de notre environnement. Cependant, l'intégration des études supérieures d'art dramatique dans l'Espace Européen de l'Enseignement Supérieur, avec la présence dans son plan d'études d'une matière de formation de base dénommée pédagogie, rend nécessaire la considération du domaine où les spécialistes en pédagogie théâtrale devront développer leurs activités. Avec ce travail nous offrons une approche théorique au domaine de l'éducation théâtrale, en faisant une proposition de systématisation, avec des implications évidentes dans son étude du point de vue scientifique et dans la formation de formateurs.

Mots clés: éducation théâtrale, pédagogie du théâtre, expression dramatique, expression théâtrale, théâtre dans l'éducation. 


\section{INTRODUCCIÓN ${ }^{1}$}

El 5 de junio de 2010, el Boletín Oficial del Estado publicaba el Real Decreto 630/2010 que establece el contenido básico de las enseñanzas artísticas superiores de arte dramático, reguladas en la Ley Orgánica 2/2006, de 3 de mayo, de Educación, y ordenadas en el RD 1614/2009, de 26 de octubre, publicado en el $B O E$ de 27 de octubre de 2009. El Anexo I del citado RD 630/2010, que define el perfil de los titulados, señala que se trata de profesionales capacitados para el ejercicio de la "docencia", razón por la que el Anexo II, que establece las materias de formación básica, incluye la que se denomina "pedagogía". Una materia² que habrá de proporcionar la formación necesaria para que aquéllos puedan ser competentes en el campo de la educación y la animación teatral, atendiendo a su descriptor:

Conocimiento de las teorías de la educación, del aprendizaje y de la psicología del desarrollo. Conocimiento y práctica de procesos de diseño y desarrollo curricular, planificación didáctica y elaboración de materiales para la práctica educativa y la animación teatral. Conocimiento de los principios teóricos y metodológicos que orientan el diseño, desarrollo y evaluación de procesos de enseñanza y aprendizaje y de programas de animación teatral, en función de diferentes espacios, tiempos y beneficiarios. Conocimiento, análisis y práctica de métodos y estilos de enseñanza, aprendizaje y animación. Conocimiento de los aspectos básicos de la historia de la educación y de la animación teatral. Estudio de casos y análisis de buenas prácticas. La investigación aplicada a la educación y la animación teatral. Políticas de garantía y gestión de calidad (BOE, 2010, 137, 48476).

Con este trabajo nos proponemos ofrecer una descripción pormenorizada (Eisner, 1998, 78) del conjunto de prácticas que situamos bajo el sintagma de «educación teatral", y establecer una sistematización de lo que, con Bourdieu (1995), definimos como campo, y, al mismo tiempo, incidir en una necesaria "formación de criterio" a favor del teatro como ámbito de educación general y como ámbito de educación especializada (Touriñán y Longueira, 2009), sin olvidar que el propio campo constituye un ámbito de investigación especialmente relevante para los profesionales de la educación teatral, y puede, y debiera, tener una incidencia positiva en su formación permanente, sin olvidar un grupo creciente de titulados en arte

1. El texto que presentamos se vincula al Proyecto de Investigación "De los tiempos educativos a los tiempos sociales: la construcción cotidiana de la condición juvenil en una sociedad de redes. Problemáticas y alternativas pedagógico-sociales", del que es IP José Antonio Caride, subvencionado mediante convocatoria pública por la Secretaría de Estado de Investigación, Desarrollo e Innovación del Ministerio de Economía y Competitividad en el marco del Plan Nacional de I+D+i (convocatoria 2012), con el código EDU2012-39080-CO7-01, con financiamiento de la Unión Europea a través de los fondos FEDER.

2. Además de profesor asociado en la Universidad de Vigo, quien subscribe es, desde 2005, año de su creación, director y profesor en la Escuela Superior de Arte Dramático de Galicia, en el Departamento de Teoría e Historia de las Artes Escénicas y en el área de pedagogía teatral. 
dramático que realizan estudios de postgrado, ávidos de iniciar su andadura investigadora enfrentando problemas tan substantivos y relevantes como los educativos.

Partimos de una lectura empírica, nacida de la experiencia propia, mas tamizada por una perspectiva sistémica (Colom, 2002), enriquecida con aportaciones de numerosos autores que se han ocupado del campo, o de campos limítrofes (Caride, 2005), sin olvidar la visión histórica, que ya reclama una bibliografía sistemática (Vieites, 2012b). Y todo ello teniendo presentes los fundamentos que deben guiar una investigación educativa (Sabariego y Bisquerra, 2004), que, en este caso, busca mostrar la configuración de un campo especialmente rico pero poco explorado, y mucho menos de forma integral. Salvo excepciones, el universo de la educación teatral en España no ha suscitado miradas globales, si bien se han realizado estudios parciales substantivos (Tejerina, 1994; Soria Tomás, 2010), y se han defendido tesis doctorales especialmente relevantes en ámbitos específicos. A partir de esas aportaciones ofrecemos nuestra propuesta de (re)construcción del campo.

Resulta necesario, en efecto, definir el campo en el que desarrollar esa función docente en la que los titulados superiores en arte dramático ${ }^{3}$ habrán de ser competentes, lo que tendrá especial relevancia a la hora de concretar la formación inicial que esa nueva área, "pedagogía", entendida como una "pedagogía del teatro", habrá de ofrecerles. Es importante subrayar el hecho de que esa presencia de la pedagogía teatral en la trayectoria formativa de los que serán egresados en arte dramático supone reconocer, de facto, un ámbito de educación específico, que, con este trabajo, queremos definir y delimitar, y que también debiera tener especial relevancia en la consideración de la pedagogía teatral como especialidad de estudios (Vieites, 2011). Para ello, partimos de miradas complementarias:

- En primer lugar nos ocupamos de la dimensión axiológica, que nos ayude a determinar el porqué y el para qué de la educación teatral.

- Luego ofrecemos una visión del campo como sistema, para buscar la mirada más adecuada al objeto (Morin, 1996, 81), y mostrar su riqueza en la perspectiva de la investigación educativa, que tanta incidencia puede tener en la formación permanente del profesorado.

3. El 13 de enero de 2012 la Sala de lo Contencioso-Administrativo, Sección cuarta, del Tribunal Supremo, hacía pública una sentencia en la que estimaba el recurso de la Universidad de Granada contra la denominación de "grado" para los estudios superiores de enseñanzas artísticas, lo que implica que, en breve, con la entrada en vigor de la Ley Orgánica de Mejora de la Calidad Educativa, estos estudios recuperarán la anterior denominación de "título superior", una situación insólita por cuanto en la mayoría de los países en que se pueden cursar tales estudios, éstos se sitúan en el ámbito universitario, lo que viene a mostrar cuánto camino queda por hacer en este campo para una verdadera convergencia con Europa. Un problema que se podría solucionar de inmediato con la incorporación de centros y enseñanzas a la universidad, aprovechando todas las posibilidades de esa integración. 
- A continuación consideramos, en una perspectiva fenoménica, los escenarios de tal educación, partiendo de la ya clásica tripartición del universo educativo (Coombs y Ahmed, 1975, 27).

- Finalmente, señalados los espacios y tiempos en los que la educación teatral está presente (e incluso ausente), y definidas sus tipologías básicas, mostramos que se trata de un vasto campo de investigación de carácter esencialmente educativo, con un enorme potencial para el desarrollo de las disciplinas que le son propias, para la formación del profesorado y para el fomento de la pedagogía teatral, disciplina fundamental en proceso de construcción (Vieites, 2013), que ya suscita, afortunadamente, un creciente interés en España (Saura, 2011).

Como conclusión, formulamos una propuesta de sistematización, premisa fundamental en la necesaria normalización de unas enseñanzas con un considerable potencial educativo (Bolton, 1991; Gallagher y Booth et al., 2003), que invitan a la apertura y promoción de interesantes líneas de investigación (Taylor et al., 1996; Ackroyd et al., 2006), pero también para el desarrollo ulterior de una especialidad propia de estudios, similar a la que encontramos en países como Brasil, Argentina, México, Colombia o Inglaterra (Alfonso, 2011).

\section{LA EDUCACIÓN TEATRAL EN LA PERSPECTIVA AXIOLÓGICA}

En su consideración de la educación musical como campo, Touriñán y Longueira (2010) proponían un acertado juego preposicional (educar "para", "por"), que, en el caso de la educación teatral, se había aplicado ya en un trabajo en el que podemos leer:

Estamos, pues, ante un campo de practicas educativas..., sumamente rico que muestra las potencialidades de la educación teatral, en tanto resulta posible educar con, desde, por, para y en el teatro. Por eso queremos destacar, de partida, que cuando hablamos de formación o de educación teatral no nos referimos en exclusiva a la que sería propia de actores, actrices, directores y otros trabajadores y trabajadoras de la escena, sino a ese rico y diverso campo de practicas educativas que conforman... el objeto de estudio de la Pedagogía teatral (Vieites, 2005, 33).

Si bien el número de preposiciones pueda ser excesivo, nos invita a un análisis exhaustivo de las finalidades de la educación teatral, en función de usuarios, tiempos y espacios. Proponemos ahora reducirlas a tres: en el teatro, para el teatro y por el teatro, y señalamos que la palabra teatro se utiliza en toda la diversidad de acepciones que puede abarcar. 


\subsection{La educación en el teatro}

El teatro no es tanto un medio, o recurso, cuanto "el medio". Un marco para la experiencia en el que realizar un conjunto muy variado de actividades, dentro de las que se consideran dos grandes áreas de trabajo: la expresión dramática y la expresión teatral (Landier y Barret, 1991). Hablamos de áreas y no de materias, aunque haya materias que puedan tomar esa denominación como asignaturas. Aquí aparece el problema de las denominaciones que se les puedan dar, y que no siempre han sido las más acertadas (Mantovani, 1980, 130; Courtney, 1989, 26); un problema substantivo (Núñez Cubero y Navarro Solano, 2007) que no abordaremos ahora, aunque señalamos que:

La diferencia básica que existe entre la expresión dramática y la expresión teatral radica en que en la primera lo esencial es el desempeño de roles en el marco de una acción dramática en que todos participan, en tanto en la segunda la acción dramática se organiza a partir de la consideración de un marco teatral, lo que implica tomar conciencia de los roles de actor y espectador. La expresión dramática se sitúa en el ámbito de la vida en tanto la expresión teatral pertenece al dominio del arte (Vieites, 2012a, 3).

Esta propuesta de consideración de la educación teatral en dos grandes áreas parte de los usos que hacemos de la conducta dramática, en tanto asentada en roles (Rocher, 1985). Por una parte, nos sirve en nuestra vida diaria (Burke, 1945; Goffman, 1959) y, por otra, sustenta, como medio de expresión, el arte que denominamos teatro. Pero tanto la expresión dramática como la expresión teatral, en el ámbito de la educación general, implican la puesta en marcha de procesos formativos que no se vinculan de forma explícita con el teatro como manifestación artística. Hablamos de un conjunto de competencias vinculadas con sociabilidad, comunicación, creatividad, resolución de problemas, cooperación, espontaneidad, juego y desarrollo de roles o comprensión de la alteridad (Coburn-Staege, 1977), que se relacionan con una racionalidad pedagógica centrada en el sujeto (Gozálvez Pérez, 2010).

La finalidad de esta modalidad de educación teatral, como también ocurre con la musical (Longueira, 2012; López Quintás, 2013), es la formación integral del individuo, particularmente en el ámbito de lo que se han considerado competencias básicas, transversales en las primeras etapas educativas. Con todo, su presencia no se puede limitar a tales etapas, en tanto debe estar al alcance de todo tipo de usuarios, en una acción educativa orientada al desarrollo integral de la persona. Entonces, la expresión dramática se vincula con el desarrollo personal en un marco grupal, en tanto la expresión teatral se vincula con una creación artística, de base colectiva y comunitaria, que persigue finalidades que prevalecen a las puramente artísticas. Señalaba Slade $(1978,33)$, en un trabajo pionero, que "drama significa "actuar" y "contender"”... Es el arte de vivir", y por ello también son importantes las prácticas teatrales presentes en centros escolares, que persiguen una vivencia de la cultura asentada en la experiencia, pero, igualmente, la adquisición de valores muy 
vinculados con las competencias básicas (Cervera, 1982; Torras i Albert, 2012), en ocasiones utilizando objetos con un indudable valor pedagógico, como los títeres (Oltra Albiach, 2013).

\subsection{La educación para el teatro}

El teatro, como actividad y/o profesión escénica, es la finalidad última de las prácticas educativas que cabe agrupar en esta tipología, con una considerable heterogeneidad. Hablamos de una verdadera formación profesional, y no cabe sorprenderse del uso del término "profesional" pues durante muchos años tal fue la denominación de escuelas de ingeniería o arquitectura; en Yale University se conserva aún la denominación "professional schools" para centros entre los que está su "School of Drama". Además del proceso de configuración de los estudios superiores de arte dramático (Turina, 1994), no podemos olvidar la formación orientada a otros agentes del sistema teatral, entre los que también consideramos a los espectadores, y es así que aquí podremos nombrar desde un curso de formación en comedia del arte para actores, hasta un curso sobre teatro japonés en un club de espectadores. Pero también todas aquellas áreas de formación que se ocupan de la gestión o de la tecnología teatral, y que a menudo se olvidan, como si el teatro fuese patrimonio exclusivo de artistas. Educar para el teatro implica educar a todas las personas que trabajan en el campo o se sitúan en él, en procesos diversos que abarcan estudios reglados y oficiales, y estudios igualmente formalizados pero sin validez académica oficial, como es el caso de la oferta del Centro de Tecnología del Espectáculo, dependiente del Instituto Nacional de las Artes Escénicas y de la Música (Larrañaga, 2006), sin olvidar muchas otras actividades de formación que podríamos considerar en lo que se viene denominando educación no formal y/o abierta (Sarramona, Vázquez y Colom, 1998).

\subsection{La educación por el teatro}

Esta modalidad nace del hecho de que a través de la expresión dramática y de la expresión teatral, y de actividades de factura diversa que les son propias, se desarrollan acciones de formación vinculadas a contenidos de otras áreas como historia, geografía, geometría o conocimiento del medio natural (Jackson et al., 1993), pero también como complemento de la formación inicial o permanente en otras especialidades de estudio y en otros campos profesionales. Aquí, el juego del teatro se convierte en instrumento gracias a procedimientos como la dramatización, el juego dramático, el juego de roles, la creación colectiva, las lecturas dramatizadas, la dicción y la expresión oral, o la plástica teatral (Motos y Tejedo, 1987). Son técnicas que se ponen al servicio de otros procesos de enseñanza y aprendizaje con sus finalidades propias, a los que se suman actividades que no se desarrollan en el ámbito formal, pues en diversos campos de intervención 
socioeducativa se hace uso de técnicas dramáticas, sea en campañas de animación a la lectura o en programas de educación vial o ambiental, por poner ejemplos bien conocidos (Taylor, 1985). Un caso interesante es el de la pedagogía terapéutica, con prácticas que se sitúan entre las ciencias de la salud, las ciencias de la conducta y las ciencias de la educación (Jennings et al., 1994). Las experiencias y posibilidades en estos ámbitos son muy numerosas, tantas que su número invita a desarrollar investigaciones específicas.

En los casos (1) y (2) estaríamos hablando, en sentido estricto, de educación teatral, en tanto el "teatro" es el medio y/o el fin del proceso educativo, en tanto en (3) el teatro no siempre es el medio, y nunca es el fin del proceso, o no debiera serlo. Y al hablar de medio lo hacemos en la doble acepción del término: como recurso a través del que hacemos algo y como marco en el que hacemos algo, con todas las implicaciones que tiene la creación de un marco lúdico de expresión y comunicación concebido como espacio transicional de interacción simbólica (Winnicott, 1971). En (3) el teatro es un procedimiento que se puede utilizar, o no, en función de variables varias, pero aun cuando se utilice no es el único recurso, pues hay otros tan singulares e importantes, siempre en función de la disciplina de que se trate.

De ahí que, en una primera propuesta de diferenciación, podamos hablar de una educación teatral (ET) orientada a la formación académica y profesional específicamente teatral, y de una ET orientada a una formación integral. También se considera aquella educación por el teatro que se vincula con otros saberes y ámbitos del hacer. Tendríamos entonces una ET general y una ET especializada, sin olvidar esa ET procedimental o aplicada, que situamos a medio camino entre ambas, y utilizamos el condicional porque es probable que en algún momento se propongan denominaciones más precisas que susciten un amplio consenso entre la comunidad educativa. En todo caso, estas tres modalidades básicas de educación teatral parten de unos principios comunes, que derivan de la propia naturaleza de lo teatral, asentada en el hecho de que la expresión dramática, en el plano de la experiencia, sirve de base a la expresión teatral, en el plano del arte de la escena. Entre esos principios, cabría, cuando menos, destacar los que siguen:

- Creación de un marco de experiencia (Goffman, 1974) de carácter ficcional y lúdico, asentado en la capacidad de la persona para jugar (Caillois, 1967), para jugar a ser otro, en lo que se ha definido como «juego protagonizado" (Elkonin, 1980), sea en función de las necesidades de la existencia, sea en un proceso de expresión extracotidiano y en ocasiones de naturaleza artística (Schechner, 2002).

- Uso del rol, vinculado con la generación de la acción (Luckmann, 1996), la situación, el conflicto y los universos de ficción (Dolezel, 1999), que tienen un anclaje en lo real y lo reproducen, lo que implica una replica, o reconstrucción, de procesos vida (Watzlawick, Bavelas y Jackson, 1991, 141). 
- Exploración, desarrollo y uso específico, y muy especializado, de los recursos expresivos de la persona, especialmente en lo que atañe a la expresión oral, la corporal o la gestual (Barker, 1977), y en todo lo que tiene que ver con el uso del espacio con fines expresivos y comunicativos, como señalaron las investigaciones pioneras de E. T. Hall o R. L. Birdwhistell (Winkin et al., 1984).

- $\quad$ El uso permanente del rol, bajo el principio del "hacer como si", se asienta en la capacidad de jugar (Huizinga, 1972), pues, como decía Peter Brook (2010, 189), ya en 1968, "una obra de teatro es juego". Un juego que parte de una premisa básica del pensamiento hipotético-deductivo: ¿Qué pasaría si...? Se pone de manifiesto en el título de un libro editado en 1978 en Italia, Io ero l'albero (tu il cavallo), con experiencias de Franco Passatore, Silvio Destefanis, Ave Fontana y Flavia De Lucis. En esa proposición de juego, "yo era el árbol" y "tú el caballo", se contiene el principio fundamental que tanta consternación causaba a Hamlet, en la escena 2 del acto segundo de la obra homónima de William Shakespeare, al contemplar, aquél, demudado, como un comediante se emocionaba hasta la conmoción al recuperar las palabras dolidas de Hécuba: "What is Hecuba to him, or he to Hecuba / that he would weep for her?".

- Uso específico de la situación, que se crea a partir de unas circunstancias dadas y configurando su propio "cronotopo" (Bajtín, 1989), como marco en el que se produce la interacción y el conflicto, y su necesaria resolución (O’Toole, 1992), si bien siempre se pueda dar el caso de finales abiertos que muestran nuevos conflictos, como ocurre con Casa de muñecas, el drama de Henrik Ibsen. Todo ello conduce a que los jugadores deban desarrollar lo que hemos definido como "dramaturgia de la situación" (Vieites, 2010), en tanto adecuación de la conducta a las exigencias de cada nueva situación en función del estándar que determinen los horizontes de expectativas (Giner, 2010), y utilizando la improvisación como estrategia de adaptación de la conducta (Hodgson y Richards, 1982).

- Un proceso de relación permanente con la alteridad, con el otro y con lo otro, que en todo caso implica una mirada al yo, tal y como podremos comprobar en textos como Medea, de Eurípides, o Los cuernos de don Friolera, de Ramón María del Valle Inclán, y siempre en un contexto de ficción, generado por el mágico "como si".

- Un proceso permanente de interacción grupal, que demanda habilidades y competencias en relación, expresión y comunicación, sea con los que forman parte del grupo, con los que conforman el universo de ficción, o con los que integran el público.

De estas características que definen lo dramático y lo teatral, deriva la dimensión educativa de esas dos grandes áreas básicas: la expresión dramática y la expresión teatral, que ya ponían de manifiesto trabajos pioneros de Harriet FinlayJohnson, en 1912; A. T. Craig, en 1913, o Caldwell Cook, en 1917, y que señalaban, 
desde su propia experiencia en el aula, cómo la participación en espectáculos teatrales era una escuela de vida y favorecía el desarrollo personal (Redington, 1983; Bolton, 2009). Tanto la expresión dramática como la expresión teatral favorecen aquellos aprendizajes que no hace tanto se consideraron pilares básicos en educación (Delors, 1996).

\section{LA EDUCACIÓN TEATRAL EN LA PERSPECTIVA SISTÉMICA}

Partimos ahora del análisis lo que pueda ser el subsistema de la educación teatral, como parte del sistema educativo (García Aretío, 1989). Autores diversos (Fernández Torres, 2000; Fernández Vieites, 2010) han mostrado lo que pudiera ser una visión sistémica del campo teatral partiendo de las propuestas de la Teoría General de Sistemas (Luhmann,1990) y considerando la trascendencia que pueda tener en la teoría y la historia del teatro o en la consideración de políticas teatrales sistémicas, también en el plano educativo (Vieites, 2007). Son líneas interesantes de estudio del campo a partir de elementos y funciones, que cabría poner en relación con la educación teatral, por las posibilidades de un enfoque sobre el que Bunge $(2002,57)$ dirá: «Puesto que el mundo es un sistema, también debe serlo nuestro conocimiento de él.. Se propone entonces considerar:

- Los agentes de la ET, para establecer quién participa en la formación teatral, de una forma directa o indirecta. Consideramos al profesorado y al alumnado, en sus tipologías y características, y prestando especial atención a su proceso de configuración como sujetos (de educación), sin olvidar aquellos agentes que en el pasado operaban en una dinámica formativa no escolar, como los actores con compañía propia, en prácticas muy extendidas en los siglos XIX y XX, vinculadas con la formación en el puesto de trabajo, dentro de la compañía y bajo la guía del primer actor (Fernán Gómez, 1985), y presentes en otras compañías con maestros tan notables como Meyerhold o Chaikin (Ruiz, 2008). En el caso del profesorado, cabría considerar su cualificación, su formación inicial y permanente, los procedimientos de habilitación, y otras cuestiones vinculadas al acceso al ejercicio profesional docente (Soria Tomás y Pérez-Rasilla, 2008), prestando especial atención a la formación de aquel profesorado que se ocupa de las actividades teatrales en escuelas e institutos (Deldime et al., 1991). También es importante considerar su trayectoria artística, docente o investigadora, y la escuela o escuelas y tradiciones escénicas y pedagógicas con las que se vincula. En igual medida, cabría realizar un análisis sistemático del alumnado, considerar necesidades de formación y expectativas, sea en relación con la educación obligatoria sea en relación con aquella con una dimensión profesional. También es interesante analizar su procedencia, nivel de estudios, edad, sexo o profesión, así como conocer las actitudes y expectativas con las que los padres y madres 
deciden que sus hijos participen en actividades extraescolares vinculadas con el teatro, en tanto pueden ofrecer valiosos testimonios en relación con sus potencialidades percibid as y las realizaciones contrastadas. Un ámbito de investigación relevante y substantivo.

- Los tiempos y los espacios de la educación, pero también sus modalidades y tipologías, así como las diferentes disciplinas a que ha dado lugar la ET en su desarrollo como campo, todo lo cual guarda relación con los ámbitos de la formación, con sus finalidades y orientaciones, y con sus áreas de conocimiento: interpretación, dirección escénica, escenografía, dramaturgia, animación teatral, expresión oral, iluminación, caracterización, expresión corporal... Por esta vía nos adentramos en la historia de las disciplinas escolares (Viñao, 2006) o la historia del currículum, en la que emerge, como ámbito destacado, la historia de los estudios de declamación o arte dramático.

- Los productos de la ET, que van desde los diferentes diplomas que se han considerado y otorgado en cada caso (y el modelo de formando o egresado que configuran) a los muy diversos materiales educativos que se elaboran, entre los que destacaron en su día los manuales de declamación (Rubio Jiménez, 2002), textos escolares para la práctica del teatro que cuentan con antecedentes tan notables como el Natya Shastra indio (escrito entre el 200 ANE y el 200 y atribuido a Bharata) o el Fushikaden japonés, escrito por Zeami Motokiyo en el siglo XV. Cabría considerar también las culturas propias del mundo educativo (empírica, normativa y científica), que se manifiestan en la historia de la educación teatral (Escolano, 2002), y las diferentes normativas que se desarrollan tanto en el nivel de la administración pública como en el de los centros (leyes, decretos, órdenes, disposiciones, normas internas, reglamentos, contratos). También podríamos considerar la producción editorial vinculada con la educación teatral, desde editoriales específicas hasta publicaciones y revistas específicas; el trabajo difusor que en su día realizó la revista Cuadernos de Pedagogía, o la promoción que se realiza a día de hoy desde la Editorial Ñaque y desde su revista Expresión, o en revistas como Primer Acto, ADE/Teatro o Acotaciones; sin olvidar, en ningún caso, su creciente presencia en revistas de educación de reconocido prestigio.

- Los procesos de la ET, prestando especial atención a la docencia, al aprendizaje, los métodos de evaluación, la transición a la vida activa, la organización de los centros, el acceso del alumnado, la elaboración de planes de estudio o de programas docentes. Un ámbito muy interesante, ligado con la docencia, tiene que ver con las corrientes, escuelas y metodologías de trabajo dominantes en cada momento en cada disciplina o área de conocimiento, y con los modelos de actividad formativa presentes en los diferentes tiempos, espacios e instituciones (Fliotsos y Medford et al., 2004). En esa dirección, situados en el campo de la educación 
superior, cabría considerar el desarrollo de líneas propias de trabajo así como la apropiación de las procedentes del exterior, particularmente en los años sesenta y setenta, en que se dan a conocer creadores y formadores tan dispares como Stanislavski, Artaud o Grotowsky, y en esa misma dirección, el modo en que esos modelos que llegan de fuera inciden en la praxis escénica y en la formación (López Antuñano, 2013). De igual modo, se puede considerar el impacto de determinadas tendencias en la educación teatral general, que aparecen en escuelas de verano como la de Acción Educativa en Madrid, la Escola d'Expressió del Ayuntamiento de Barcelona o PROEXDRA en Granada; todo un movimiento, amplio y heterogéneo, todavía por estudiar ${ }^{4}$.

- Las instituciones de la ET, entre las que cabe destacar compañías de teatro, escuelas de interpretación, conservatorios de declamación, universidades, institutos de segunda enseñanza, escuelas de educación básica, colegios mayores, residencias, asociaciones, fundaciones o escuelas superiores de arte dramático (Graells, 1990; Granda, 1994). Como se dijo, un ámbito relevante es el de las escuelas de verano, que en los años sesenta y setenta del siglo pasado desarrollaron una importante labor de renovación pedagógica que, en el caso que nos ocupa, se concretó en la organización de cursos que constituyeron, en muchas ocasiones, el único marco para la formación y/o actualización del profesorado (Groves, 2011).

- Las estructuras de la ET, para ver en qué medida los agentes del campo han creado redes, grupos, asociaciones, festivales o plataformas (Henríquez, 2004). En el ámbito de la educación teatral propia de las primeras etapas educativas cabe destacar, por ejemplo, la existencia de asociaciones de carácter nacional e internacional, en casos agrupadas en plataformas como IDEA (acrónimo de la International Drama/Theatre in Education) o Assitej (Association Internacionale du Théâtre pour l'Enfance et la Jeuneusse).

- Las funciones de la ET, vinculadas a la formación teatral general, la especializada, o la complementaria, aplicadas a usuarios diferentes en tiempos diversos, pero igualmente con otras finalidades de similar importancia como el desarrollo personal, el desarrollo comunitario o la intervención socioeducativa, situados ya en el campo de la animación teatral y de la pedagogía social (Caride y Vieites et al., 2006).

- Los contornos de la ET, en tanto la educación teatral forma parte de un ámbito mayor, las enseñanzas artísticas, pero también guarda relaciones

4. En marzo de 1991 el Ayuntamiento de Tarragona publicaba el número 0 de Homo Dramaticus, que se definía como Revista Internacional d'Expressió Dramàtica, y que recogía las ponencias presentadas en el I Congreso Internacional de Teatro en la Educación, celebrado en la ciudad entre el 18 y el 23 de marzo de aquel año. La experiencia no tendría continuidad. 
evidentes con otros campos como la educación física y deportiva (Montávez Marín, 2012), la educación social o el trabajo social, sin olvidar su relación con disciplinas y tradiciones de difícil ubicación en la actualidad como la oratoria o la retórica (Lucas, 2008), y señalando su relación evidente con el campo de las ciencias de la salud, a través de las terapias expresivas (Moccio, 1990).

Sería deseable, finalmente, operar en una perspectiva comparada, considerando variables geográficas y culturales, pues las dinámicas internas del campo en España se relacionan con las dinámicas de otros países, sin olvidar lo acontecido en cada una de las comunidades autónomas, y hacerlo todo, además, en cada una de las temáticas más arriba propuestas, lo que aumenta más, si cabe, la amplitud del campo y nos da una idea del trabajo inmenso que resta por hacer.

\section{LA EDUCACIÓN TEATRAL EN LA PERSPECTIVA FENOMÉNICA}

Considerando los escenarios de la educación desde la conocida tripartición del universo educativo, cabría considerar una educación teatral informal, otra formal y otra no formal, siendo la primera la que el individuo realiza a lo largo de su vida mediante las experiencias diarias y su relación con el medio; la segunda la que se corresponde con el sistema educativo, y la tercera la que estando organizada y sistematizada se realiza fuera de un marco oficial y/o no conduce a una titulación oficial (Trilla, 1996).

Sin embargo, dudamos que se pueda hablar de educación informal en aquellos casos en que no existe una intencionalidad educativa por parte del emisor y/o del receptor, o no se da una comunicación bidireccional. No hay duda de que de la lectura de un programa de mano del Festival de Teatro Clásico de Olite se puede derivar un aumento del caudal de conocimientos del lector, y de que la contemplación de un espectáculo puede ser fuente de conocimiento, pero resulta difícil conjugar una voluntad educativa por parte de un emisor, que necesariamente condicionaría la dimensión formal y los contenidos del mensaje, y la misma voluntad por parte de un receptor, lo que modificaría su recepción. Esa educación informal, a veces denominada difusa, en realidad no es educación, en tanto definamos ésta como un proceso de comunicación entre dos personas en las que una de ellas asume el rol discente y la otra el rol docente. Y para nosotros, educación es, ante todo, un proceso de comunicación, intencional y voluntario (Sarason, 1999). Por eso, en nuestra consideración del universo configurado por la educación teatral, proponemos diferenciar entre procesos reglados, no reglados y abiertos, términos más operativos en el campo en que nos situamos:

- La formación reglada sería aquella que está presente en el currículum oficial y que, en consecuencia, se imparte en centros oficiales, y que presenta una cierta diversidad pues va desde los cursos de formación ocupacional a las titulaciones superiores y a las universitarias de grado. Hablamos 
de los títulos que ofrece una escuela superior de arte dramático, de la materia "Artes escénicas" que se cursa en el bachillerato de música y artes escénicas, o de los cursos contemplados en la familia profesional de "Arte y Artesanía" ${ }^{5}$, de la que tomamos como ejemplo el siguiente: "ART523_3 Construcción de decorados para la escenografía de espectáculos en vivo, eventos y audiovisuales".

- La educación no reglada puede darse en muchas academias, centros de formación y otros espacios de acción cultural y socioeducativa, en procesos sistemáticos, organizados y que pueden conducir a la obtención de diplomas y otros reconocimientos, pero que carecen de validez oficial. Como ejemplo tenemos el Centro de Tecnología del Espectáculo, creado en 1988 y dependiente del Instituto Nacional de las Artes Escénicas y de la Música, y que cuenta con una interesante oferta educativa. Otra línea de trabajo muy importante es el de las escuelas municipales de teatro, con programas formativos diversos, pero también la que desarrollan compañías y/o salas de teatro, además de asociaciones profesionales de actores, directores de escena o técnicos del espectáculo.

- Finalmente hay que decir que en muchos de esos espacios y entidades se ofrecen programas de formación en los que puede participar cualquier persona, sea como docente sea como discente, pues en la formación abierta cabe un conjunto muy diverso de actividades y su carácter va a depender de la institución o entidad que las organice. A veces es asumida por instituciones como las universidades a través de las aulas de teatro, que en unos casos apuestan por establecer una especie de gradación de los cursos (más formalizados) y en otros casos ofrecen programas libres (por tanto más abiertos), pero otras veces son asociaciones de vecinos, culturales o recreativas, las que desarrollan tales programas, con una orientación más participativa, integradora y comunitaria, y con una vocación decidida por la participación.

Se configura así un universo educativo rico, heterogéneo y que ofrece una considerable disparidad de espacios, tiempos, usuarios y finalidades, que a día de hoy en España todavía espera estudios sistemáticos, para los que este trabajo aspira a ofrecer un marco básico de referencia.

\section{LA EDUCACIÓN TEATRAL EN SU PRAXIS}

Consideramos ahora los escenarios en que está presente la educación teatral, o pudiera estarlo, y en cualquiera de las modalidades antes señaladas, renunciando,

5. Desarrollada en el Real Decreto 145/2011, de 4 de febrero, publicada en el BOE del 24 de febrero. 
por razones obvias, a ofrecer referencias para todos los señalados, también por el hecho de su considerable disparidad y dispersión. Entendemos que la panorámica que presentamos, sobre todo en sus categorías, pudiera servir, siguiendo el ejemplo del Centro de Investigación MANES o de la History of Education Society, para inventariar, recuperar, mantener y divulgar el rico patrimonio que ha generado la educación teatral en su historia y en su presente, al menos en lo que se refiere a trabajos de divulgación, estudios, investigaciones, tesis doctorales, relatos de experiencias, materiales gráficos y audiovisuales, y otros documentos.

\subsection{Centros educativos de enseñanza obligatoria}

- En educación infantil y primaria no existen materias vinculadas con la educación teatral toda vez que la expresión dramática, que contemplaba la LOGSE, y que finalmente no se impartió, desaparece con la LOE, y no se recupera en la LOMCE. Hay centros, sin embargo, que, de forma voluntaria, incluyen clases obligatorias u optativas de expresión dramática o dramatización en el currículo. Sí está presente, en muchos casos, la práctica del teatro a través de las actividades extraescolares, sea en las orientadas a desarrollar destrezas y capacidades específicas, sea en talleres específicos más orientados a la realización de un espectáculo.

- En educación secundaria obligatoria no existen materias vinculadas con la educación teatral. Algunos centros han conseguido el reconocimiento de materias optativas con denominaciones diversas como «expresión teatral", "taller de teatro" o, simplemente, "teatro". Como en el caso anterior, existe un considerable número de centros que cuentan con grupos de teatro en el marco de las actividades extraescolares.

- En centros y/o aulas de educación especial y atención a la diversidad, se suelen utilizar recursos de carácter dramático o teatral como dramatizaciones, juegos y animaciones, si bien las experiencias son poco conocidas. Nos situamos en el territorio de la pedagogía terapéutica con base teatral, muy desarrollada en otros países (Grady, 2000).

\subsection{Centros educativos de enseñanza postobligatoria}

- $\quad$ En bachillerato la enseñanza teatral está presente en el de artes, opción de música y artes escénicas, que contempla una materia denominada "Artes escénicas", con cuatro horas semanales y que se puede impartir en primer o segundo curso. Aquí, como en casos anteriores, aparece el problema del profesorado, pues en la inmensa mayoría de los casos no se trata de un profesorado cualificado especialmente, lo que da una idea del escaso nivel de normativización de la educación teatral en España. En estos momentos la docencia de la materia citada la asume profesorado de 
lengua y literatura, lo que le confiere una dimensión más teorética que práctica.

- En formación profesional no existen, a diferencia de otros países, ciclos formativos específicos. En un primer momento, el Ciclo Superior de Animación Sociocultural incorporaba un módulo de formación en expresión teatral que desapareció con la regulación definitiva de los ciclos de grado medio y de grado superior. Desde el Institut del Teatre de Barcelona se viene insistiendo en la necesidad de crear una familia profesional vinculada con las artes del espectáculo, y su Escuela Superior de Técnicas de las Artes del Espectáculo supone un ejemplo a seguir por las titulaciones que ofrece, en colaboración con la Universidad Politécnica de Cataluña, como títulos propios de ésta.

- La formación profesional ocupacional no destaca por potenciar una oferta vinculada con las actividades escénicas, si bien existen cursos específicos como los que contemplan las familias profesionales en Artes y Artesanía, Imagen Personal o Imagen y Sonido.

\subsection{Centros educativos de enseñanza superior}

Es aquí donde encontramos una casuística considerable, sobre todo teniendo en cuenta la mayor autonomía de los centros a la hora de incorporar materias, siquiera optativas, al currículum.

- Materias de carácter teatral presentes en muchas titulaciones en numerosas universidades (Reverte y Oliva et al., 1996).

- Titulaciones propias. En la Universidad de La Coruña se puso en marcha hace años un título propio en Pedagogía teatral, equivalente a una diplomatura (Rodríguez López-Vázquez, 2001).

- Titulaciones oficiales que se imparten en las escuelas superiores de arte dramático, en las especialidades de interpretación, escenografía y dirección escénica y dramaturgia, o grados en artes escénicas que imparten algunas universidades públicas y privadas.

- Posgrados. En la actualidad varias universidades (Complutense, Murcia, Vigo, País Vasco, Rey Juan Carlos) ofrecen estudios de posgrado vinculados con las artes escénicas y con la educación teatral.

\subsection{Otros centros y espacios}

- Aulas de teatro universitarias, con una larga trayectoria que se remonta a los años cincuenta y sesenta, pero que ya tienen precedentes a inicios del siglo XX. La casuística es muy diversa pues las actividades se orientan tanto a ofrecer una formación teatral básica como a promover la realización y difusión de espectáculos. 
- Escuelas municipales de teatro. Se trata de entidades que ofrecen variados programas de formación orientados a colectivos diversos, desde programas de formación de actores y actrices hasta talleres de teatro para la infancia, la juventud o la tercera edad. Se da una considerable heterogeneidad, por lo que encontramos propuestas como aquellas que quieren desarrollar un programa de formación en interpretación hasta aquellas que se orientan a programas mucho más vinculados con la animación teatral de base.

- Escuelas de teatro y centros privados de formación teatral. En unos casos se ofrecen programas de varios años de formación y en otros cursos monográficos en las más diversas disciplinas. Su variedad y diversidad es enorme; a veces se vinculan con un profesional de prestigio, mientras que en ocasiones forman parte del proyecto de una compañía de teatro.

- Compañías y salas de teatro que, de forma permanente u ocasional, según los casos, ofrecen programas variados; como ejemplo cabría citar la trayectoria de la Sala Cuarta Pared de Madrid, la Sala Beckett de Barcelona, el Teatro de la Estación de Zaragoza o el Teatro del Norte de Oviedo.

- Instituciones, fundaciones, asociaciones y entidades diversas. Organizan cursos de formación inicial y permanente, de actualización y de divulgación. La casuística es muy variada y cabría considerar aquí todo el vasto campo del teatro aficionado y el teatro comunitario.

Hasta aquí una breve exposición de los espacios que se ocupan de la educación teatral, o que se ocuparon en el pasado, de sus escenarios. Como hemos visto, en la mayoría de los casos se ofrecen programas de formación no reglada y/o abierta, si bien en los espacios de formación reglada también caben las dos modalidades anteriores. Un campo enorme, sumamente productivo que espera estudios sistemáticos.

\section{UN VASTO CAMPO DE INVESTIGACIÓN}

El citado Real Decreto 630/2010, que regula los estudios superiores de arte dramático en España, también señala, con notable claridad, algunos retos de los centros que los imparten. En su preámbulo se afirma que «la consolidación de líneas de investigación y creación, la formación de creadores e investigadores son aspectos imprescindibles a fomentar y considerar por parte de las instituciones públicas y privadas", y un poco más adelante, ya en el apartado 4, del artículo 2, se afirma que:

Los centros de enseñanzas artísticas superiores de Arte dramático fomentarán programas de investigación científica y técnica propios de esta disciplina, para contribuir a la generación y difusión del conocimiento y a la innovación en dicho ámbito. Las Administraciones educativas establecerán los mecanismos adecuados para que estos centros puedan realizar o dar soporte a la investigación científica y 
técnica, que les permita integrarse en el Sistema Español de Ciencia y Tecnología (BOE, 137, 2010, 48468).

Pero todavía en el Anexo i, en el que se define el perfil profesional de los titulados en las diferentes especialidades, establece, para cada una de las tres contempladas, que "este profesional estará capacitado para el ejercicio de la investigación...". Tomando en consideración las finalidades formuladas en el Real Decreto, una promoción efectiva de una investigación específica, capaz de impulsar la integración de los centros en el Sistema Español de Ciencia y Tecnología, debiera considerar cuestiones substantivas, siendo la más importante la de incorporar las enseñanzas artísticas a la universidad, con lo que muchas problemáticas podrían resolverse a corto o medio plazo. Pero, además, habría que considerar qué tipo de investigación es pertinente en el campo de las artes escénicas, cuáles serían las metodologías y las herramientas más adecuadas, y cuáles los cauces para la divulgación y transferencia del conocimiento generado. Cabría entonces considerar cómo investigar y para qué investigar, si bien de partida habría que decidir qué investigar.

Las prácticas educativas que hemos venido considerando hasta el momento, en toda su heterogeneidad, constituyen un ámbito específico y especializado de investigación, que puede ser especialmente pertinente y prioritario en centros, como los superiores, en los que se habrán de combinar líneas de trabajo centradas en (1) la investigación sobre la creación y (2) la investigación sobre la formación. Se configura así un ámbito que podría ser especialmente productivo en cuanto las escuelas superiores de arte dramático desarrollen líneas de investigación en relación con las disciplinas que conforman el currículo, con las metodologías docentes más adecuadas en cada caso, pero igualmente en relación con el propio universo de la educación teatral, o con la construcción de la pedagogía teatral y de las diferentes didácticas específicas propias de las disciplinas que conforman ese universo, en sus dimensiones teórica, metodológica, práctica o histórica.

A modo de inventario urgente, cabría considerar, entonces, una serie de líneas de trabajo especialmente relevantes en una perspectiva educativa y en una dimensión estratégica. A saber:

- La dimensión educativa del teatro en una doble perspectiva, como ámbito de educación general (en el teatro) y como ámbito específico de educación (para el teatro).

- La dimensión procedimental de estrategias, técnicas y procedimientos de carácter dramático y teatral (educar por el teatro), en relación con múltiples prácticas educativas y beneficiarios.

- La historia de la educación teatral, en toda la heterogeneidad señalada en las páginas precedentes, y de la propia pedagogía teatral; es decir, historia de las prácticas educativas y del pensamiento pedagógico y teatral subyacente a las mismas, sin olvidar las instituciones del campo como conservatorios, escuelas o compañías de teatro (Vieites, 2014). 
- $\quad$ La historia del currículum propio de la enseñanza teatral, sean asignaturas concretas, sean especialidades de estudio, como las que se han desarrollado en los conservatorios de declamación y en las escuelas superiores de arte dramático.

- La historia de las disciplinas escolares propias del campo.

- El desarrollo del marco teórico y conceptual, del discurso educativo y/o artístico, en suma, de cada disciplina o asignatura.

- El estudio del teatro escolar (en los diferentes niveles educativos) como práctica cultural, educativa y artística en sus aspectos históricos, teóricos, metodológicos, empíricos y artísticos.

- La consideración de los métodos de enseñanza, estilos de aprendizaje y modelos de evaluación específicos y/o pertinentes en educación teatral.

- La educación teatral en relación con otras áreas de conocimiento, como la psicología del desarrollo, los procesos psicológicos básicos, la antropología, la sociología o las teorías de la comunicación.

- La cuestión trascendental de la formación de formadores para las diferentes tipologías de educación teatral (en, para y por, el teatro).

- La historia de la investigación teatral en una perspectiva educativa.

- La formación de investigadores en educación y pedagogía teatral.

El desarrollo de proyectos de investigación en los ámbitos señalados tendría, sin lugar a dudas, tres consecuencias inmediatas: (a) el aumento exponencial del conocimiento científico en torno a la educación teatral, (b) la (re)conversión del profesorado de las escuelas superiores de arte dramático y de otros centros de similar orientación en verdaderos especialistas en docencia e investigación de su área de conocimiento y (c) la transformación substantiva de los centros en espacios de investigación y el desarrollo de una necesaria interacción entre su cultura empírica y su cultura científica (Ruiz Berrio et al., 2000).

\section{CONCLUSIÓN}

Como colofón, y conclusión, de nuestra panorámica, proponemos una taxonomía de la educación teatral, que pueda definir áreas de investigación específicas, y líneas en el proceso de formación de aquellas personas que habremos de considerar especialistas en educación teatral. En consonancia con todo lo dicho, cabría hablar de:

- Una educación teatral de carácter general, orientada a la formación integral del ser humano y con un carácter propedéutico que no se vincula con lo teatral (en tanto profesional), presente desde la escuela infantil hasta cursos de desarrollo personal para personas adultas.

- Una educación teatral aplicada, procedimental e instrumental en otros procesos de enseñanza y aprendizaje no propios de lo teatral, y que 
admite muy diversos desarrollos en muchos ámbitos de la formación inicial y permanente.

- Una educación teatral específica, finalista en muchos casos, que admite varias orientaciones y diferentes niveles de profundización o cualificación, y por ello se puede transitar desde una formación inicial, propia del bachillerato, de un curso de formación ocupacional o de un curso de iniciación en una escuela municipal de teatro o aula universitaria, a un programa de formación más especializado en una escuela de teatro o en una compañía escénica. Teniendo siempre, en medio, esa formación complementaria que admite muchas variantes en función de aquello que venga a complementar, pues tanto puede servir para que una persona especializada en pedagogía social conozca técnicas teatrales, como para que un periodista televisivo conozca técnicas de expresión oral que faciliten sus competencias expresivas.

Llegaríamos así a un cuadro en el que podríamos considerar, como ya se dijo, procesos reglados, no reglados y abiertos, en tiempos y espacios diversos, y para usuarios múltiples.

GRÁFICO 1. LA EDUCACIÓN TEATRAL

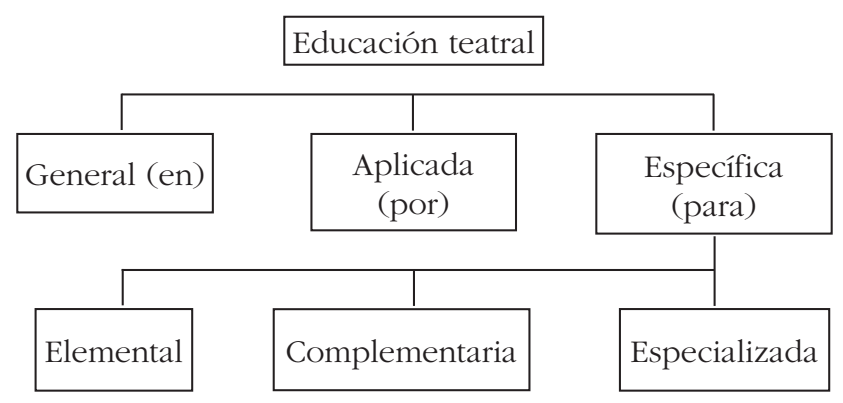

FUENTE: Elaboración propia.

Todo ello confiere riqueza al campo de investigación e, igualmente, una enorme complejidad a la formación de especialistas en educación teatral por cuanto sus ámbitos de actuación son diversos, y van desde la formación del actor al uso del teatro en procesos de desarrollo comunitario. Y así se nos muestra la necesidad de operar en dos direcciones complementarias:

- De un lado, extraer todo el potencial formativo de esa nueva materia de formación básica, denominada "pedagogía", que ya forma parte del currículo de los estudios superiores de arte dramático, también para que los futuros egresados tomen conciencia de la importancia de las ciencias 
de la educación como soporte necesario e imprescindible de la función docente.

- Del otro, considerar la posibilidad de establecer marcos de especialización en pedagogía teatral a través de estudios de posgrado, si bien en numerosos países de nuestro entorno, la formación de especialistas configura una especialidad de estudios, todo ello en función de una notable presencia de la educación teatral en el currículo de la enseñanza obligatoria y postobligatoria. Hablaríamos, entonces, de un "grado en educación teatral", que tal vez se deba construir siguiendo el ejemplo de grados similares en lo que lo substantivo de la educación se complementa con la relevancia sociocultural del adjetivo que le acompaña, como en el caso de la educación social (Caride, 2007).

De igual modo, como antes señalamos, la educación teatral nos ofrece un ámbito de investigación con muchas potencialidades, sea para justificar su normalización y normativización, como argumentaban Bolton (2009) y Ryngaert (2010), sea para desarrollar todo su potencial educativo, considerando que:

- Configura un campo de prácticas educativas de carácter general y específico y con carácter formal, no formal y abierto, con una considerable riqueza y heterogeneidad, y con dimensión histórica.

- Se desarrolla siendo parte de la educación general y obligatoria y de la educación postobligatoria, pero también forma parte del universo de la educación permanente.

- Tiene rasgos pertinentes y diferenciales en cuanto a sus principios teóricos y metodológicos, e igualmente en relación a sus finalidades y objetivos.

- Tiene carácter integral e integrador, pero también posee una dimensión profesional, sea de carácter artístico, sociocultural o educativa.

- Conforma un espacio específico y muy diverso de formación de formadores y de educadores, en campos muy diversos.

- Es el objeto de estudio de una disciplina en proceso de construcción, la pedagogía teatral, que se ocuparía del estudio sistemático del campo, como señalamos en un trabajo reciente en el que presentábamos el programa central de la disciplina (Vieites, 2013, 503). Entendemos que esta disciplina, la pedagogía teatral, tiene un alcance mayor que aquel que tradicionalmente se le ha concedido, limitando a veces su campo al ámbito de la educación básica para acabar por definirla como una "didáctica" de la expresión dramática y/o teatral (Laferrière, 1997). Entendemos la pedagogía teatral como una disciplina científica que se ocupa del estudio de la educación teatral en toda su rica diversidad y pluralidad, como hemos querido mostrar en el presente trabajo.

Estamos pues ante líneas de estudio e investigación que debieran ser abordadas a través de la creación de equipos capaces de desarrollar proyectos con una 
base interdisciplinaria y orientados hacia una necesaria puesta en valor de esa disciplina denominada pedagogía teatral, por desarrollar plenamente. Un proyecto al que las escuelas superiores de arte dramático y otros centros superiores, facultades de educación incluidas, debieran tener mucho que aportar, en la necesaria generación y difusión del conocimiento sobre la educación teatral en sus dimensiones teórica, tecnológica, metodológica y práctica.

\section{REFERENCIAS BIBLIOGRÁFICAS}

AcKROYD, J. (ed.) (2006) Research Methodologies for Drama Education. Stoke on Trent, UK, Trentham Books.

Alfonso, M. (2011) Pedagogía y teatro. Revista Colombiana de Artes Escénicas, 5, 154-171.

Bajtín, M. (1989) Teoría y estética de la novela. Madrid, Taurus.

BARKER, C. (1977) Theatre Games. London, Methuen.

Bolton, G. (1991) El arte dramático, en Hargreaves, D. J. (ed.) Infancia y educación artística. Madrid, Morata, 148-168.

Bolton, G. (2009) A expresión dramática na educación. Vigo, Galaxia.

BOURDiEu, P. (1995) Las reglas del arte. Génesis y estructura del campo literario. Barcelona, Anagrama.

Brook, P. (2012) El espacio vacío. Madrid, Península.

Bunge, M. (2002) Crisis y reconstrucción de la filosofía. Barcelona, Gedisa.

BuRKe, K. (1945) A grammar of motives. New York, Prentice Hall.

CAILLOIs, R. (1967) Les jeux et les hommes. Paris, Gallimard.

CARIDE, J. A. (2005) Las fronteras de la educación social. Barcelona, Gedisa.

CARide, J. A. (2007) La Pedagogía Social ante el proceso de convergencia europea de la Educación Superior. Pedagogía Social. Revista Interuniversitaria, 14, 11-31.

CARide, J. A. y Vieites, M. F. (eds.) (2006) De la educación social a la animación teatral. Gijón, Trea.

CERVERA BORRÁs, J. (1982) Historia crítica del teatro infantil en España. Madrid, Editora Nacional.

Coburn-Staege, U. (1980) Juego y aprendizaje. Madrid, Ediciones de la Torre.

Colom, A. J. (2002) La (de)construcción del conocimiento pedagógico. Nuevas perspectivas en teoría de la educación. Barcelona, Paidós.

CoOmbs, P. H. y Ahmed, M. (1975) La lucha contra la pobreza rural. El aporte de la educación no formal. Madrid, Tecnos.

Courtney, R. (1989) Play, Drama \& Thought. Toronto, Simon \& Pierre.

Deldime, R. (ed.) (1991) Théâtre et formation des enseignants. Carnières, Belgique, Éditions Lansman.

Delors, J. (1996) Los cuatro pilares de la educación, en Delors, J. (ed.) La educación encierra un tesoro. Informe a la UNESCO de la Comisión Internacional sobre la educación para el siglo XXI. Madrid, Santillana/UNESCO, 91-103.

Dolezel, L. (1998) Heterocósmica. Ficción y mundos posibles. Madrid, Arco Libros.

EISNER, E. W. (1998) El ojo ilustrado. Indagación cualitativa y mejora de la práctica educativa. Barcelona, Paidós.

Elkonin, D. B. (1980) Psicología del juego. Madrid, Visor. 
Escolano Benito, A. (2002) La educación en la España contemporánea. Políticas educativas, escolarización y culturas pedagógicas. Madrid, Biblioteca Nueva.

FERNÁN GÓMEZ, F. (1985) El viaje a ninguna parte. Madrid, Cátedra.

FERnÁNDEZ TORRES, A. (2000) La piedra que cae en el agua. Breves reflexiones sobre la evolución del "sistema teatral" español (1940-1985). ADE/Teatro, 82, 28-39.

FERNÁNDEZ Vieites, M. (2010) As artes escénicas en Galicia. Elementos para unha diganose, en Freixanes, V. y MeIXIDE, A. (eds.) O Capital da cultura: unha achega ás industrias culturais de Galicia. A Coruña, Fundación Caixa Galicia, 463-537.

Fliotsos, A. L. y Medford, G. S. (eds.) (2004) Teaching Theatre Today. Pedagogical Views of Theatre in Higher Education. New York, Palgrave Macmillan.

Gallagher, K. y Booth, D. (eds.) (2003) How Theatre Educates. Convergences \& Counterpoints. Toronto, Toronto University Press.

García Aretio, L. (1989) La educación. Madrid, Paraninfo.

Giner, S. (2010) Sociología. Barcelona, Península.

GoffMAn, E. (1959) The Presentation of Self in Everday Life. New York, Anchor Books.

Goffman, E. (1974) Frame analysis: An essay on the organization of experience. London, Harper and Row.

GozÁlvez PÉREZ, V. (2010) Hacia una reconstrucción de la racionalidad pedagógica. Teoría de la Educación. Revista Interuniversitaria, 22, 2, 19-42.

Grady, S. (2000) Drama and Diversity. A pluralistic perspective for educational drama. Portsmouth, NH, Heinemann.

Graells, G.-J. (1990) L'Institut del Teatre. 1913-1988. Historia gräfica. Barcelona, Diputació de Barcelona.

GRANDA, J. (1994) Historia de una escuela centenaria. Madrid, RESAD.

GROVES, T. (2011) Las escuelas de verano: una reforma educativa desde abajo, en CELADA PERANDONES, P. (ed.) Arte y oficio de enseñar: dos siglos de perspectiva histórica/XVI Coloquio Nacional de Historia de la Educación. Madrid, SEDHE, 145-154.

Henríquez, J. (2004) XIX Semanas Internacionales de Teatro para Niñas y Niños. Primer Acto, 306, 109-115.

Hodgson, J. y Richards, E. (1982) Improvisación. Madrid, Fundamentos.

Huizinga, J. (1972) Homo ludens. Madrid, Alianza.

JaCKSON, T. (ed.) (1993) Learning through theatre. New persectives on theatre in education. London, Routledge.

Jennings, S. (ed.) (1994) The Handbook of Dramatherapy. London, Routledge.

LAFERRIÈRE, G. (1997) La pedagogía puesta en escena. Ciudad Real, Ñaque.

LANDiER, J.-C. y BARRet, G. (2001) Expression dramatique théâtre. Paris, Hatier.

LARRAÑAGA, P. (2006) Innovación, desarrollo y divulgación en el centro de tecnología del espectáculo. Arbor. Ciencia, Pensamiento y Cultura, 717, 67-73.

LONGUEIRA, S. (2012) Los retos educativos de la sociedad del conocimiento. Aproximación a las aportaciones desde el ámbito de la educación musical, en GArCía ArETIO, L. (ed.) Sociedad del Conocimiento y Educación. Madrid, UNED.

López ANTuÑano, J. G. (2013) Importancia y vigencia de Stanislavski. Nueva Revista de Politica, Cultura y Arte, 142, 184-199.

LóPez QuinTÁs, A. (2013) El poder formativo de la música. Revista Española de Pedagogía, $254,49-58$.

LuCAS, A. (2008) El poder de la palabra. Técnicas para hablar en público. Barcelona, Ariel. Luckmann, Th. (1996) Teoría de la acción bumana. Barcelona, Paidós. 
Luhmann, N. (1990) Sociedad y sistema: la ambición de la teoría. Barcelona, Paidós.

Mantovani, A. (1980) El teatro: un juego más. Madrid, Editorial Nuestra Cultura.

Moccio, F. (1990) El taller de las terapias expresivas. México, Paidós.

Montávez Marín, M. (2012) LOE. La consolidación de la expresión corporal. EmásF, Revista Digital de Educación Física, 14, 60-80.

MORIN, E. (1996) Introducción al pensamiento complejo. Barcelona, Gedisa.

Motos, T. y Tejedo, F. (1987) Prácticas de dramatización. Barcelona, Humanitas.

NúÑez Cubero, L. y NAVARro Solano, M. R. (2007) Dramatización y educación: aspectos teóricos. Teoría de la Educación. Revista Interuniversitaria, 19, 225-252.

Oltra Albiach, M. A. (2013) Los títeres: una herramienta para el siglo XXI. Revista Española de Pedagogía, 225, 277-292.

O’Toole, J. (1992) The Process of Drama. Negotiating Art and Meaning. London, Routledge. http://dx.doi.org/10.4324/9780203359617.

Pliego, V. (ed.) (2013) Actas de la Jornada sobre la relación del Real Conservatorio de Música de Madrid y la Universidad. Recuperado el 31 de octubre de 2013.

http://documentacion.realconservatoriodemadrid.org/informacionesJE/informacion_226/ACTAS\%20JORNADA\%202013.pdf.

Redington, C. (1983) Can Theatre Teach? A Historical and Evaluative Analysis of Theatre in Education. Oxford, Pergamon Press.

REverTe, C. y Oliva, C. (eds.) (1996) I Congreso Iberoamericano de Teatro. Pedagogía teatral: concepto y métodos. Cádiz, FIT y Universidad de Cádiz.

ROcher, G. (1985) Introducción a la sociología general. Barcelona, Herder.

Rodríguez López-VÁzQuez, A. (2001) Unha proposta universitaria para o ensino do teatro. Pedagoxía teatral. Revista Galega de Teatro, 29, 44-47.

Rubio JiménEZ, J. (2002) Los tratados de declamación y las enseñanzas teatrales en los siglos XVIII y XIX. ADE/Teatro, 92, 120-129.

Ruiz, B. (1980) El arte del actor en el siglo XX. Bilbao, Artezblai.

RUIz BerRio, J. (ed.) (2000) La cultura escolar de Europa. Tendencias históricas emergentes. Madrid, Biblioteca Nueva.

RYNGAERT, J.-P. (2010) Jouer, repésenter. Paris, Armand Colin.

Sabariego Puig, M. y Bisquerra Alzina, R. (2004) Fundamentos metodológicos de la investigación educativa, en Bisquerra Alzina, R. (coord.) Metodología de la investigación educativa. Madrid, La Muralla.

SARASON, S. B. (2002) La enseñanza como arte de representación. Buenos Aires, Amorrortu. Sarramona, J.; VÁzQuez, G. y Colom, A. J. (1998) La educación no formal. Barcelona, Ariel.

SAURA, J. (2011) Principios elementales de pedagogía teatral. ADE/Teatro, 136, 126-143.

Schechner, R. (2002) Performance Studies. An Introduction. New York, Routledge.

SLADE, P. (1978) Expresión dramática infantil. Madrid, Santillana.

SORIA TOMÁs, G. (2010) La formación actoral en España. La Real Escuela Superior de Arte Dramático (1831-1857). Madrid, Fundamentos.

Soria Tomás, G. y Pérez-Rasilla, E. (2008) Documentos sobre los profesores de las enseñanzas teatrales del Conservatorio Nacional de Música y Declamación (1931-1939), en DoméNech Rico, F. (coord.) Teatro español. Autores clásicos y modernos. Homenaje a Ricardo Doménech. Madrid, Fundamentos.

TAYLOR, J. L. (1985) Guía de simulación y de juegos para la educación ambiental. Ginebra, Unesco.

TAYlor, Ph. (ed.) (1996) Researching Drama and Arts Education. London, The Falmer Press. 
TejerINA, I. (1994) Dramatización y teatro infantil. Madrid, Siglo XXI.

TORRAS I ALBERT, A. (2012) El teatro en la Escuela: Un proyecto Municipal de incentivación del teatro como actividad formativa, cultural y artística. Dedica. Revista de Educação e Humanidades, 2, 201-216.

Touriñán, J. M. y Longueira, S. (2009) Formación de criterio a favor de la música como ámbito de educación. Bordón, 61 (1), 43-60.

Touriñán, J. M. y Longueira, S. (2010) La música como ámbito de educación. Educación "por" la música y educación "para" la música. Teoría de la Educación. Revista Interuniversitaria, 22, 2, 151-181.

Trilla, J. (1996) Otras educaciones. Barcelona, Anthropos.

TuRINA, J. L. (1994) El estado actual de las enseñanzas de música, danza y arte dramático. Arte, Individuo y Sociedad, 6, 87-104.

Vieites, M. F. (2005) Educación teatral e estudos de arte dramática, en Caride, J. A.; Trillo F. y Vieites, M. F. Arte dramática e función docente. Compostela, Consello da Cultura Galega, 15-138.

Vieites, M. F. (2007) Política teatral: en defensa del modelo sistémico. ADE/Teatro, 118, $15-26$.

VieITES, M. F. (2010) De la teatrología: ¿Disciplina o marco disciplinar?, en VIEITES, M. F. y Rodríguez, C. (eds.) Teatrología. Nuevas perspectivas. Ciudad Real, Ñaque, 12-35.

VieITES, M. F. (2011) De la pedagogía teatral: disciplina académica, área de conocimiento y especialidad de estudios. ADE/Teatro, 136, 144-159.

Vieites, M. F. (2012a) Después de la LOE. Presente y futuro de la educación teatral en España en los inicios del siglo XxI. Don Galán, 2. Recuperado el 31 de octubre de 2013. http://teatro.es/contenidos/donGalan/donGalanNum2/.

Vieites, M. F. (2012b) Para unha historia da educación teatral el Galicia. Aspectos básicos. Sarmiento. Anuario galego de historia da educación, 16, 81-100.

Vieites, M. F. (2013) La construcción de la pedagogía teatral como disciplina científica. Revista Española de Pedagogía, 256, 493-508.

VIEITES, M. F. (2014) La educación teatral: nuevos caminos en historia de la educación. Historia de la Educación. Revista Interuniversitaria, 33 (en prensa).

VIÑAO, A. (2006) La historia de las disciplinas escolares. Historia de la Educación. Revista Interuniversitaria, 25, 243-269.

Watzlawick, P.; Bavelas, J. B. y Jackson, D. D. (1991) Teoría de la comunicación humana. Barcelona, Herder.

Winkin, Y. (ed.) (1984) La nueva comunicación. Barcelona, Kairós.

Winnicott, D. W. (1971) Playing and Reality. London, Tavistock. 